\title{
Investigation of Temperature Distribution Performances of Three Different Heat Exchanger Models for Exhaust Gas Waste Heat Energy Recovery System Used with Thermoelectric Generator in Gasoline Engines
}

\author{
Haluk Güneş ${ }^{1}$ \\ 0000-0002-0915-0924 \\ ${ }^{1}$ Department of Motor Vehicles and Transportation Technologies, Tavsanl Vocational School, Dumlupinar University, Kutahya, 43300, Turkey
}

\begin{abstract}
In this study, examination of the temperature distribution for three different heat exchanger models for exhaust gas waste heat recovery systems to be used in internal combustion motorcycle engines has been made. Simulations of the models have been made by means of ANSYS Workbench Fluent software and comparative results have been put forward. It has been taken into consideration that the selected heat exchanger models have generable geometries. Model no. 1 is inclined to the outlet from the inlet by $5^{\circ}$, model no. 2 has three steps each of which has a gradient of $20^{\circ}$, and model no. 3 has a fixed section width which is parallel to exhaust gas transfer. Moreover, in model no. 3, a heat sink has been placed into the exhaust gas. On cold surfaces, the highest and the lowest temperatures have been measured respectively as $337.937 \mathrm{~K}$ and $329.465 \mathrm{~K}$ in model no. 1 , as $342.875 \mathrm{~K}$ and $329.639 \mathrm{~K}$ in model no. 2 , and as $363.897 \mathrm{~K}$ and $354.995 \mathrm{~K}$ in model no. 3. The difference between the lowest and the highest temperatures is observed as in models no. 2 and 3. With relation to the temperature distributions on hot surfaces of TEGs, the lowest and the highest temperatures are respectively as $508.631 \mathrm{~K}$ and $402.742 \mathrm{~K}$ in model no. 1 , as $510.092 \mathrm{~K}$ and $409.632 \mathrm{~K}$ in model no. 2, and as $536.595 \mathrm{~K}$ and $510.633 \mathrm{~K}$ in model no. 3 It has been observed that the lowest difference of temperature occurred in model no. 3 . When the results are examined, it is seen that the best temperature difference and the highest temperature value have been achieved in model no. 3 .
\end{abstract}

Keywords: Motorcycle engines, Heat exchanger, Heat transfer, Thermoelectric generator
Research Article

https://doi.org/10.30939/ijastech..973694

Received 22.07.2021

Revised $\quad 15.08 .2021$

Accepted $\quad 17.09 .2021$

* Corresponding author

Haluk Güneş

haluk.gunes@dpu.edu.tr

Address: Department of Motor Vehiclesi Tavsanli Vocational School, Dumlupinar University, Kutahya, Turkey.

Tel: +902746148672

\section{Introduction}

The accepted paper must be prepared in two columns. The main text of the manuscript must be written in Times New Roman, font 10, 12-point line spacing. The font size, line spacing, and margin of the template must not be altered. Authors can use this template document to prepare the manuscript to submission. Authors can find and download this Microsoft Word document from the website of the journal, www.ijastech.org, Other submission versions will not be accepted, so, the manuscript could not go further to reviewing process.

Automobiles are developing thanks to technological advancement and transform into vehicles to which more and more people have access. However; while the increase in the number of automobiles facilitates the human life, the resources consumed to own them continue to disrupt the balance of the World and result in environmental problems such as climate change and global warming. Accordingly, the issues, related to reduction of the impact of such environmental problems in all kind of processes, from production to usage, from supply of raw material to economic life, have been the subject of various scientific researches. Among such issues, primary ones include usage of recyclable materials, recovery of waste energy and low emission rates during operation [1-3]. Exhaust gas waste heat recovery systems constitute a significant place in terms of energy recovery in internal combustion engines (ICE). Generation of electricity with thermoelectric generators (TEG) by using exhaust gas temperature is one of the leading ones [4-6].

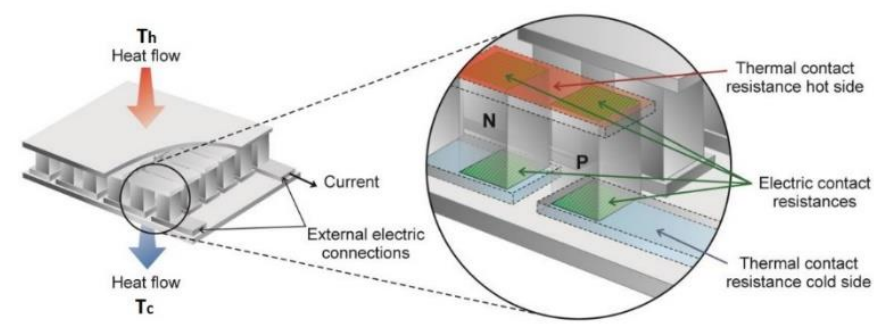

Fig. 1. Internal structure and components of thermoelectric generator [7] 
TEGs shown in Figure 1 are produced by placing semiconductors between two ceramic materials. The semi-conductors are tied by copper wires. The temperature difference occurring between the ceramic surfaces provide acquisition of electrical power at outlet edges. The amount of the energy depends on the increase in such temperature difference [8].

Areas of usage of TEGs become widespread day by day [9]. They can be confronted in many areas, from military implementations to home-related usage. However, they could not be able to provide the desired impact as their efficiency is low. In addition, high temperature, lack of cooling cold surfaces and increase in internal resistance are other negative aspects [10].

TEGs find an area of usage at every point where heat energy is available in automobiles. One of such areas is the air conditioner. Attar has put forward such issue in his study and also stated that the TEGs of today still do not provide the desired efficiency [11]. Wang et al. have used two types of heat exchangers whose internal structures are different in order to generate electricity from exhaust gas waste heat energy, and examined distributions of heat, temperature and pressure [12]. Massaguer et al. have designed a waste heat recovery system (ATEG) together with the TEG and put forward electricity generation performance of the system under fixed and driving conditions. As a result, they have explained that the speed of the vehicle and the temperature of the exhaust gas are significant factors with relation to electricity generation performance of the system [13]. Burnete et al. have compared two exhaust gas recovery systems that use different cooling methods in a vehicle with internal combustion engine (ICE) [14]. In this study, the impact of the electrical energy, generated in case of cooling the cold surface of TEGs by water and air, has been searched. They have mentioned that when TEGs cool at lower temperatures and with higher air flow rate, a higher output power is obtained. Gou et al. have compared the results of the experiment and calculations in their study, and put forward that temperature distribution of the cold surface is of great importance in terms of enhancing electricity generation performance of TEGs [15].

In this study, comparison of simulation figures of three different heat exchanger models, designed for generating power exhaust gas waste heat energy of vehicles with ICE, has been included. During simulations, Fluent programme has been used. Temperature distributions and temperature differences of TEGs on hot and cold surfaces have been examined comparatively.

\section{A waste heat recovery system}

In waste heat recovery systems, more than one TEG are used [16]. A well established and equal temperature distribution on hot and cold surfaces of TEGs increases their performance. In this study, temperature distributions on 3 different heat exchanger models that have three-dimensional geometry shown in Figure 2 have been examined. During simulations, Ansys Workbench 18.1 fluent programme, computational fluid Dynamics (CFD) and finite elements model have been used. In order to accelerate the calculations, the models have been contemplated symmetrically, and the calculations have been made by dividing them into two.

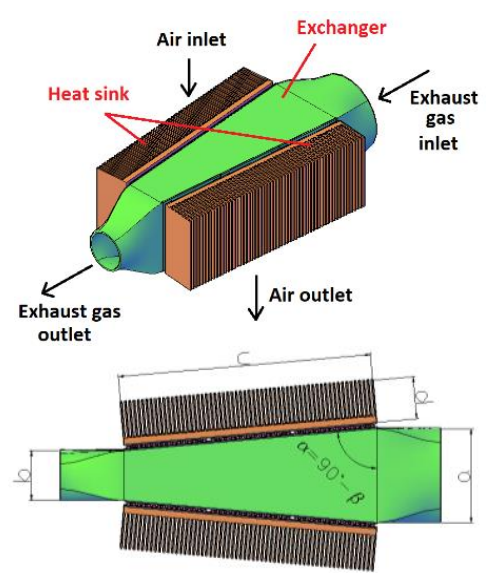

Number 1 (a)

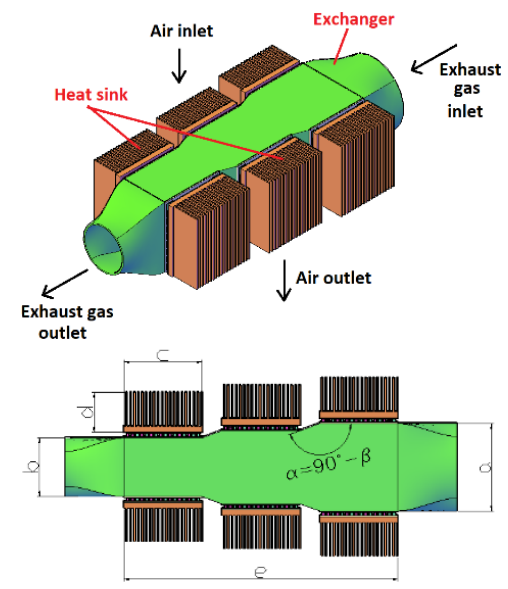

Number 2 (b)

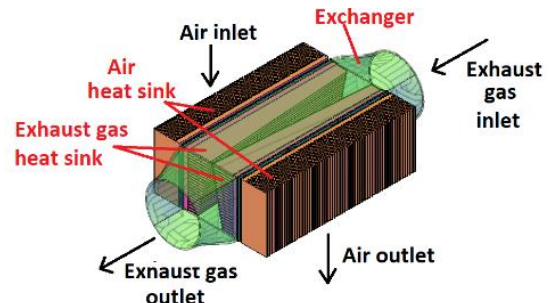

outlet

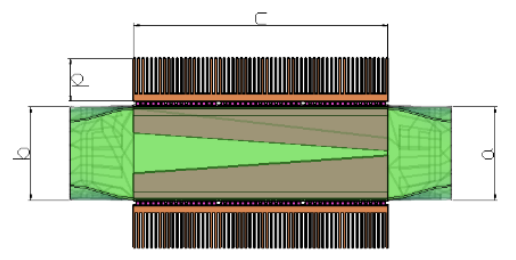

Number 3 (c)

Fig. 2. Isomeric and top views of the heat exchangers, which have been compared, as inclined by $5^{\circ}$ (a), as gradual inclined by $20^{\circ}(\mathrm{b})$, and as placed heat sink inside the exhaust gas (c)

In exhaust gas heat energy recovery systems, TEGs contact with different exhaust temperatures as the gas cools of gradually when such TEGs are lined next to each other in parallel with the gas flow. At inlet and outlet areas of the exhaust gas, an approximate temperature difference of $323 \mathrm{~K}$ occurs. Hot parts of TEGs, which are close to the initial inlet point that are hotter when compared to other points of the exhaust gas, get heated more than the ones which are close to the outlet point of the exhaust gas. Such situation negatively affects heating of hot parts of TEGs at different temperatures, their internal resistance changes and power generation performances. These designs have been studied in order to eliminate this uneven temperature distribution. In Table 1, basic sizes of the models used in the design are given.

Table 1. Basic sizes of the geometries used

\begin{tabular}{c|c|c|c|c}
\hline Symbol & Unit & Model 1 & Model 2 & Model 3 \\
\hline $\mathrm{a}$ & $\mathrm{mm}$ & 44.50 & 44.50 & 44.50 \\
\hline $\mathrm{b}$ & $\mathrm{mm}$ & 23.50 & 30.00 & 44.50 \\
\hline $\mathrm{c}$ & $\mathrm{mm}$ & 120.00 & 40.00 & 120.00 \\
\hline $\mathrm{d}$ & $\mathrm{mm}$ & 20.00 & 20.00 & 20.00 \\
\hline $\mathrm{e}$ & $\mathrm{mm}$ & - & & - \\
\hline$\beta$ & degree & $5^{\circ}$ & $20^{\circ}$ & - \\
\hline
\end{tabular}


Table 2. Boundary conditions for inlet and outlet of the exhaust gas and the coolant

been designed by $5^{\circ}$ towards the exhaust gas outlet. The aim here is to increase density of the exhaust gas from the inlet to the outlet, and to make exhaust gas contact more with the final TEGs. It can be though by means of such geometry that the increase in the speed of exhaust gas towards the outlet can cause the exhaust gas entering into the system to be discharged more rapidly. Such situation can put forward as negative result in terms of temperature distribution.

In figure $2 b$, model number 2 is shown. Here, each TEG has been placed on the heat exchanger gradually by an angle of $20^{\circ}$. When compared to the first model, each of the TEGs of such design is cooled by separate coolers. Moreover, in this model, exhaust gas outlet can be wider when compared to the other. The aim here is to mitigate the situations that can create negative impact in the first design. In this design, the heat exchanger has a shrinking structure.

In Figure 2c, model no. 3 is shown. Here, a totally different geometry has been studied. 2 reciprocal heat sinks, which are parallel to the flow, have been placed inside a constant-volume heat exchanger, instead of a shrinking geometry. According to the experiences acquired in the first two simulations of the heat exchanger, the heat sinks placed inside the exhaust gas have been designed as to distribute the heat in an appropriate manner and homogenously. In Figure 3, such system and the heat sink used are shown. When such structure is examined, it is seen that the height of heat sink wings increase from the hottest part of exhaust gas inlet towards the part which is less warm.

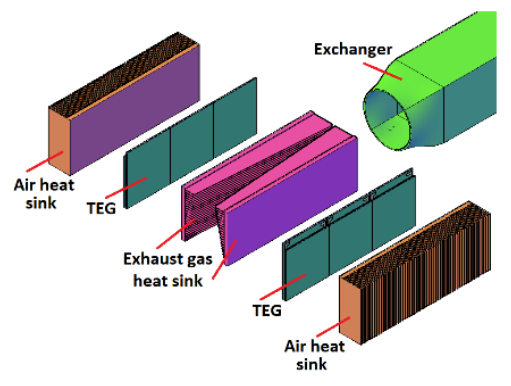

(a)

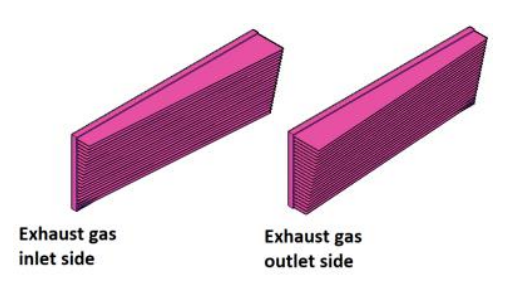

(b)

Fig. 3. Model no. 3 (a) and the heat sink placed inside it (b)

\section{Boundary conditions and basic equations}

In the models, the exhaust gas has been used as heat source, and the air has been used as coolant. Boundary conditions for exhaust gas inlet and outlet, air inlet and outlet for each of three models have been given in Table 2. Such conditions have been obtained from operating conditions of a motorcycle engine with single cylinder.

\begin{tabular}{c|c}
\hline \multicolumn{2}{c}{ Exhaust gas inlet Boundary condition } \\
\hline Velocity inlet & Temperature \\
\hline$m s^{-1}$ & $K$ \\
\hline 13.2 & 600 \\
\hline Exhaust gas outlet Boundary condition \\
\hline \multicolumn{2}{c}{ Pressure outlet } \\
\hline Air inlet Boundary condition \\
\hline Velocity inlet & Temperature \\
\hline$m s^{-1}$ & 300 \\
\hline 4.04 & Air outlet Boundary condition \\
\hline \multicolumn{2}{c}{ Pressure outlet } \\
\hline
\end{tabular}

Such engine can reach up to $8000 \mathrm{rpm}$ engine speed. However, the temperature and exhaust has speed values measured at speed condition of $4500 \mathrm{rpm}$, during which the engine is used at the highest potential, have been considered as velocity inlet boundary condition. As the outlet is towards the atmosphere, the pressure has been considered as boundary condition. Air has been supplied for the coolant by means of a fan; and velocity inlet has been used as boundary condition for the inlet, and the pressure has been used as boundary condition for the outlet as it is towards the atmosphere. The speed of exhaust gas has been measured by means of pitot tube, and the speed of air has been measured by means of an anemometer.

Table 3. Physical parameters of the materials.

\begin{tabular}{|c|c|c|}
\hline \multicolumn{3}{|c|}{ TEG } \\
\hline \multicolumn{3}{|l|}{ Insulation plates (Alumina) } \\
\hline Density & 3720 & $\mathrm{Kg} \mathrm{m}^{-3}$ \\
\hline Specific Heat & 837.36 & $J K^{-1} K^{-1}$ \\
\hline Thermal Conductivity & 35.3 & $W m^{-1} K^{-1}$ \\
\hline \multicolumn{3}{|c|}{ Semi conductor (Bismuth Telluride) } \\
\hline Density & 7700 & $\mathrm{Kg} \mathrm{m}^{-3}$ \\
\hline Specific Heat & 544.28 & $J K^{-1} K^{-1}$ \\
\hline Thermal Conductivity & 1.5 & $W m^{-1} K^{-1}$ \\
\hline \multicolumn{3}{|l|}{ Electrical conductor (Copper) } \\
\hline Density & 8978 & $\mathrm{Kg} \mathrm{m}^{-3}$ \\
\hline Specific Heat & 381 & $J K^{-1} K^{-1}$ \\
\hline Thermal Conductivity & 387.6 & $W m^{-1} K^{-1}$ \\
\hline \multicolumn{3}{|c|}{ Heat exchanger (Steel) } \\
\hline Density & 8030 & $\mathrm{Kg} \mathrm{m}^{-3}$ \\
\hline Specific Heat & 502.48 & $J K^{-1} K^{-1}$ \\
\hline Thermal Conductivity & 16.27 & $W m^{-1} K^{-1}$ \\
\hline \multicolumn{3}{|c|}{$\begin{array}{r}\text { Heat Sink (Copper) } \\
\end{array}$} \\
\hline Density & 8978 & $\mathrm{Kg} \mathrm{m}^{-3}$ \\
\hline Specific Heat & 381 & $J \mathrm{Kg}^{-1} \mathrm{~K}^{-1}$ \\
\hline Thermal Conductivity & 387.6 & $W m^{-1} K^{-1}$ \\
\hline
\end{tabular}

Physical parameters of solid materials are given in Table 3. As positive and negative semi-conductors included in TEGs display similar characteristics, it has been accepted that both of them were made from Bismuth Telluride. The heat sinks used in the coolant air and the exhaust gas were made of copper material.

On the coolant side of the system, the air is at a temperature of $300 \mathrm{~K}$ and the hydraulic radius $D_{h}(\mathrm{~m})$ in which the air enters into the system can be calculated by Equation 1, and Reynolds number can be calculated by Equation 2 .

$R_{e}=\rho v D_{h} / \mu$ 
$D_{h}=4 a b / 2(a+b)$

Here, density $\rho\left(\mathrm{kg} \mathrm{m}^{-3}\right)$ can be obtained from the table showing features of air as viscosity $\mu\left(\mathrm{kg} \mathrm{m}^{-1} \mathrm{~s}^{-1}\right)$ [17]. Moreover, the flow rate is $v\left(\mathrm{~ms}^{-1}\right)$. It is considered that air enters into the system through quadrangle geometry. It is required to find such geometry by transforming it into hydraulic radius $D_{h}(\mathrm{~m})$. As side lengths of the geometry are a and $\mathrm{b}(\mathrm{m})$, the hydraulic radius is calculated as shown in Equation 2.

$\mathrm{R}_{\mathrm{e}}$ of the exhaust gas can be calculated by Equation 1. As $\mathrm{R}_{\mathrm{e}}>4000$, the flow is accepted as turbulent [18]. During simulations, realizable method has been used within $\mathrm{k}-\varepsilon$ turbulent model. Here, density $\rho$ and dynamic viscosity $\mu$ can be calculated by Equation 3 and Equation 4 [19].

$$
\rho=5.318 \times 10^{-12}(T+273)^{4}-1.637 \times 10^{-8}(T+273)^{3}+
$$$$
1.961 \times 10^{-5}(T+273)^{2}-2(T+273)+3.205
$$

$\mu=-2 \times 10^{-11}(T+273)^{2}+6 \times 10^{-8}(T+273)+3 \times 10^{-6}$

Friction factor for turbulent flows $f$, Nusselt number $(\mathrm{Nu})$, and Prandtl number $(\mathrm{Pr})$ can be calculated by Equations 5, 6 and 7 respectively [19].

$f=A+B / R e^{1 / m}$

$N u=\frac{(0.5 f(R e-1000) P r)}{\left(1+12.7 \sqrt{0.5 f\left(\operatorname{Pr}^{1 / 3}-1\right)}\right)}$

$\operatorname{Pr}=-9 \times 10^{-13}(T+273)^{4}+2 \times 10^{-9}(T+273)^{3} 7 \times 10^{-7}(T+$

$273)^{2}-2 \times 10^{-4}(T+273)+0.7798$

As heat transfer realizes by convection on the hot side, namely the side of exhaust gas, the heat transfer convection coefficient here can be calculated by Equation 8 .

$h_{e}=N_{u} k_{e} / D$

Here, $k_{e}\left(\mathrm{~W} \mathrm{~m}^{-1} \mathrm{~K}^{-1}\right)$ refers to thermal conductivity of the exhaust gas, and $\operatorname{ve} c_{p}\left(\mathrm{~J} \mathrm{~kg}^{-1} \mathrm{~K}^{-1}\right)$ refers to specific heat capacity. There can be calculated by Equations 9 and 10 respectively [20].

$k_{e}=9 \times 10^{-12}(T+273)^{3}-5 \times 10^{-8}(T+273)^{2}+$

$1.046 \times 10^{-4}(T+273)-1.168 \times 10^{-3}$

$c_{p}=9 \times 10^{-12}(T+273)^{3}-2 \times 10^{-8}(T+273)^{2}+10^{-5}(T+$

$273)+1.537$

Here, $T\left({ }^{\circ} \mathrm{C}\right)$ refers to the temperature. The regions that are outside the boundary conditions in hot and cold sides and that are in contact with outer environment have been defined as wall boundary condition. It is also assumed that such regions have been insulated. Table 4 contains information about the mesh quality and properties of the models.
Tablo 4. Mesh properties of models

\begin{tabular}{|c|c|c|c|c|}
\hline \multicolumn{5}{|c|}{ Model no.1 } \\
\hline $\begin{array}{c}\text { Max } \\
\text { Aspect } \\
\text { Ratio }\end{array}$ & Max & $\begin{array}{c}\text { Min } \\
\text { Orthogonal } \\
\text { Quality }\end{array}$ & Nodes & Elements \\
\hline 27.378 & 0.899 & 0.10064 & 14531000 & 10227583 \\
\hline \multicolumn{5}{|c|}{ Model no.2 } \\
\hline 19.612 & 0.929 & 0.10471 & 15324027 & 10062668 \\
\hline \multicolumn{5}{|c|}{ Model no.3 } \\
\hline 37.412 & 0.982 & 0.10075 & 24069770 & 15658132 \\
\hline
\end{tabular}

\section{Findings and argument}

For three models selected at the end of the simulations, hot and cold surfaces of TEGs, heat sink surface, and the temperature distribution inside the heat exchanger have been examined. Here, the important thing is the proximity of temperature differences on cooled and heated surfaces of each TEG. In addition, low rate of temperature difference between the TEGs at the first and the last line is of great importance. In Figures 4, 5 and 6, the temperature distribution occurring on air heat sink found in the models is shown.

When temperature distributions are examined, it is observed that the temperature is higher at exhaust gas inlet and air outlet parts on the heat sink in all models. The reason of such situation can be the fact that the parts in which the air enters into the heat sink are cooled better. When the highest and lowest temperatures occurring at geometries are considered, the highest and lowest temperatures are as follows: between $337.987 \mathrm{~K}$ and $319.020 \mathrm{~K}$ in model no. 1; between $342.905 \mathrm{~K}$ and $313.619 \mathrm{~K}$ in model no. 2; and between 363.927 $\mathrm{K}$ and 339.341 $\mathrm{K}$ in model no. 3.
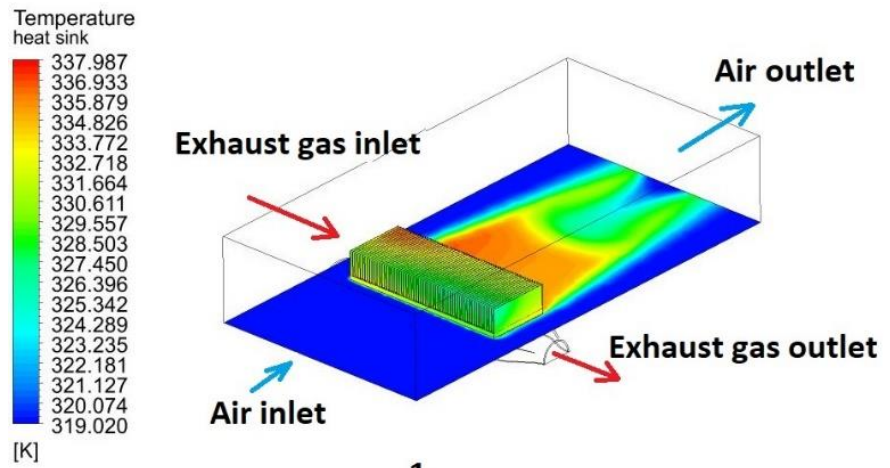

Air inlet

1

Fig. 4. Temperature distribution on the heat sink model no. 1
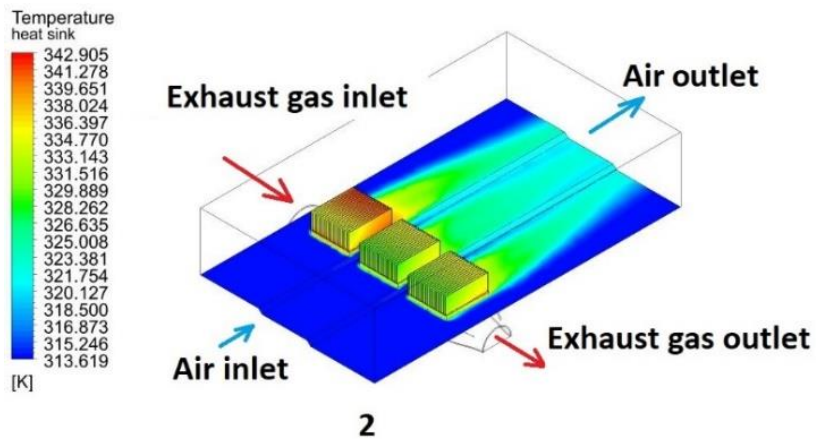

Fig. 5. Temperature distribution on the heat sink model no. 2 
In Figures 7,8 and 9, temperature distribution on cold surfaces
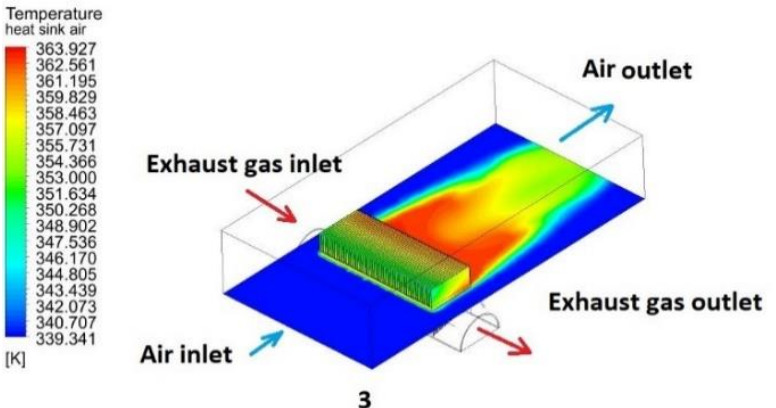

Fig. 6. Temperature distribution on the heat sink model no. 3

The heat sink in model no. 3 , gets heated much more because the heat of exhaust gas is transferred better on the TEGs by the heat sink placed inside the exhaust gas. The geometry having the lowest difference between the highest and the lowest temperature is no. 1 . The geometry which has better distribution of temperature is no. 3 . Such situation means that temperatures of cold surfaces are distributed better.
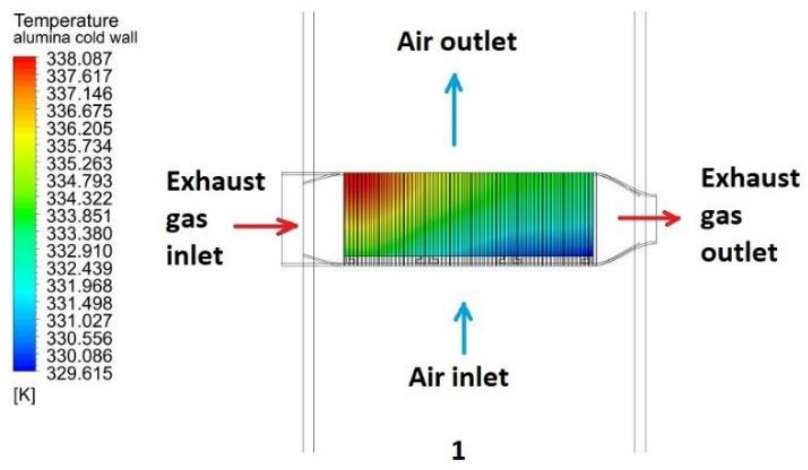

Fig. 7. Temperature distribution on cold surfaces of TEGs (Model no. 1)

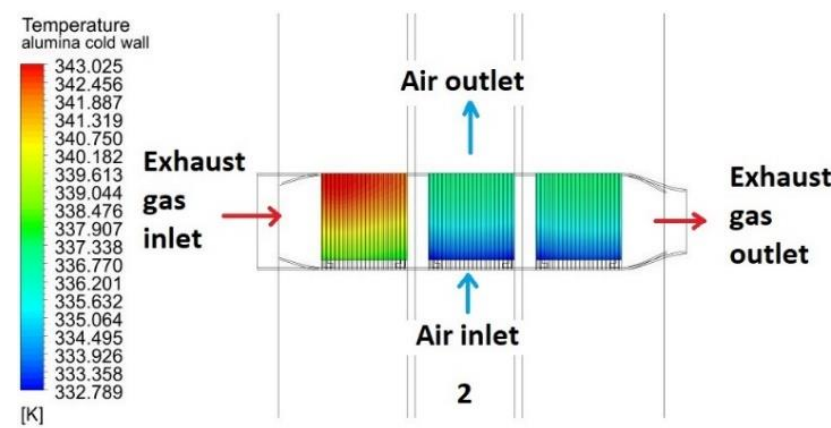

Fig. 8. Temperature distribution on cold surfaces of TEGs (Model no. 2)

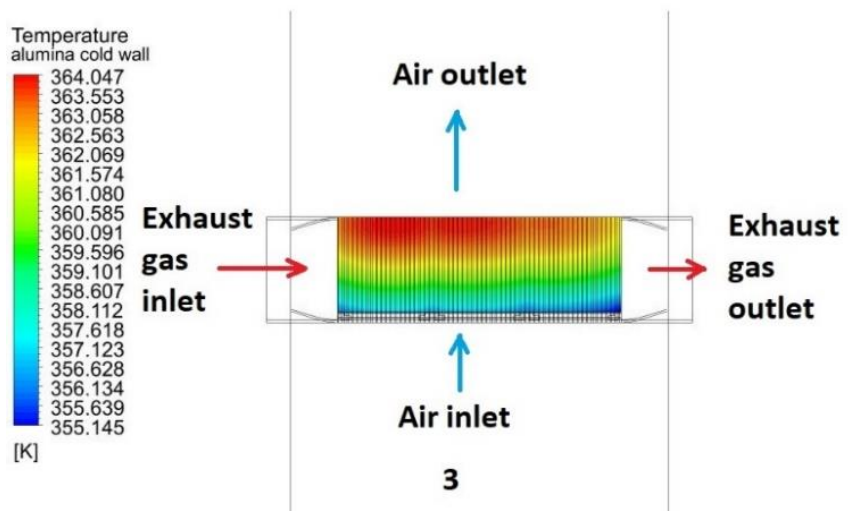

Fig. 9. Temperature distribution on cold surfaces of TEGs (Model no. 3) of TEGs are shown. In model no. 1, the highest temperature is $338.087 \mathrm{~K}$ and the lowest temperature is $329.615 \mathrm{~K}$; in model no. 2 , the highest temperature is $343.025 \mathrm{~K}$ and the lowest temperature is $332.789 \mathrm{~K}$; and in model no. 3, the highest temperature is $364.047 \mathrm{~K}$ and the lowest temperature is $335.145 \mathrm{~K}$. When such distributions are considered, it is seen that the difference between the lowest and the highest temperature occur in models no. 2 and 3. In addition, when all models have been examined, it has been observed that model no. 3 reached to the highest temperature and a homogenous distribution occurred on cold surfaces.

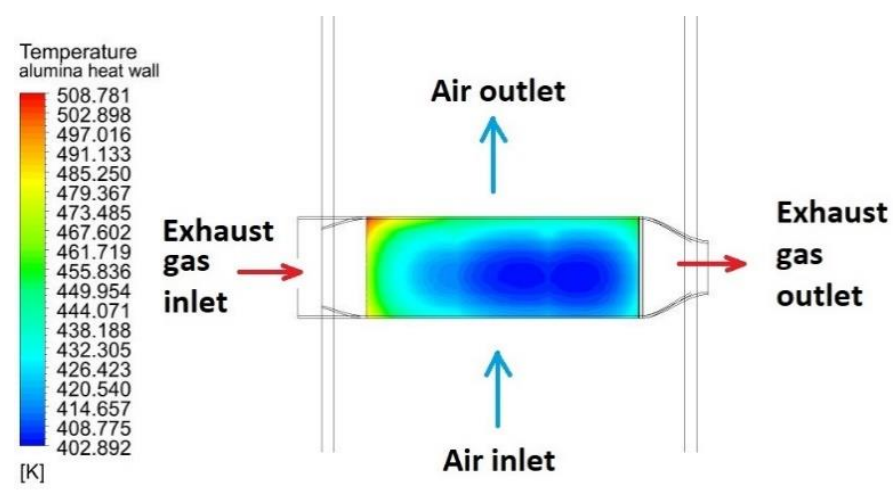

1

Fig. 10. Temperature distribution on hot surfaces of TEGs (Model no. 1)

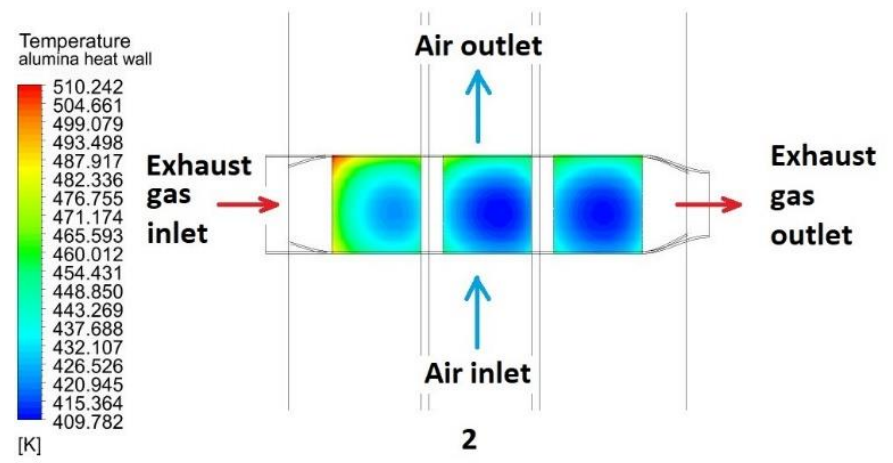

Fig. 11. Temperature distribution on hot surfaces of TEGs (Model no. 2)

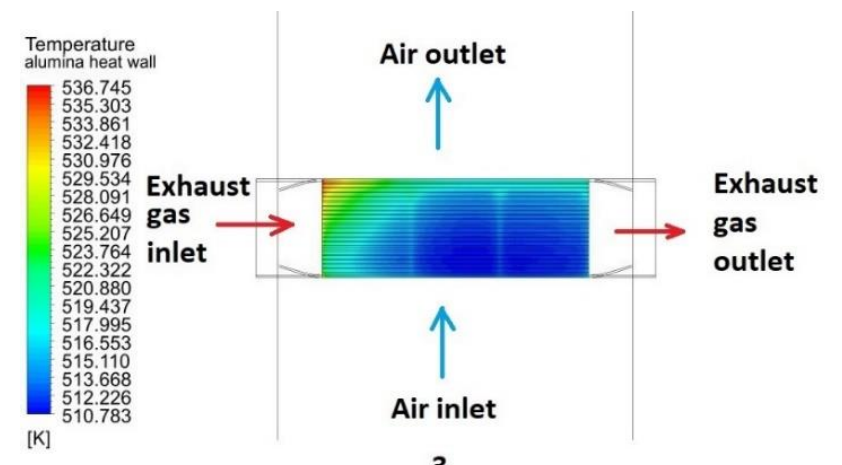

Fig. 12. Temperature distribution on hot surfaces of TEGs (Model no. 3)

In Figure 10, 11 and 12, temperature distributions on hot surfaces of TEGs are shown. It is seen that the highest temperature is $508.781 \mathrm{~K}$ and the lowest temperature is $402.892 \mathrm{~K}$ in model no. 
1 ; the highest temperature is $510.242 \mathrm{~K}$ and the lowest temperature is $409.782 \mathrm{~K}$ in model no. 2 ; and the highest temperature is $563.745 \mathrm{~K}$ and the lowest temperature is $510.783 \mathrm{~K}$ in model no. 3. Here, the lowest temperature difference occurs in model no. 3 as $298 \mathrm{~K}$ when compared to the others. It has come out that hot surfaces of TEGs are close to each other in this model.

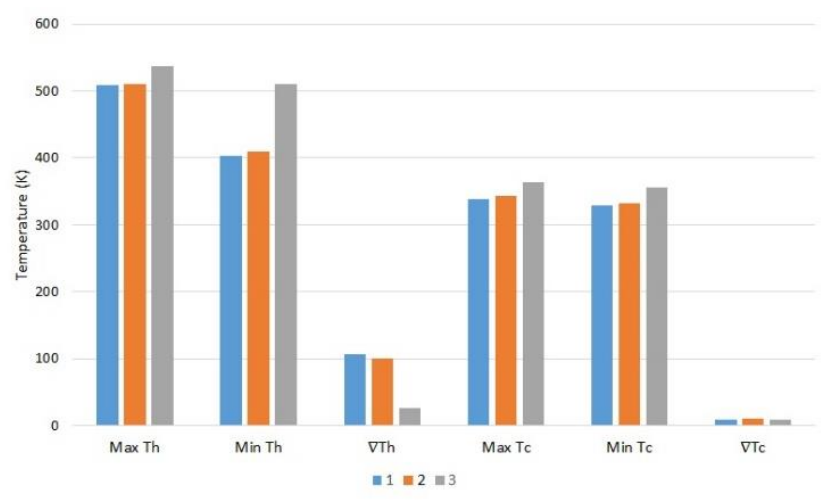

Fig. 13. Temperatures occurring on hot and cold parts of the TEGs in the models and the differences between them

In Figure 13, the highest and lowest temperatures occurring on hot and cold surfaces of TEGs and the temperatures differences between them are shown. When compared to the others, in model no. 3 , higher temperature has been reached on both hot and cold surfaces. Moreover, the difference between the highest and the lowest temperatures has been found less in model no. 3. On cold surfaces, all models have given similar results.

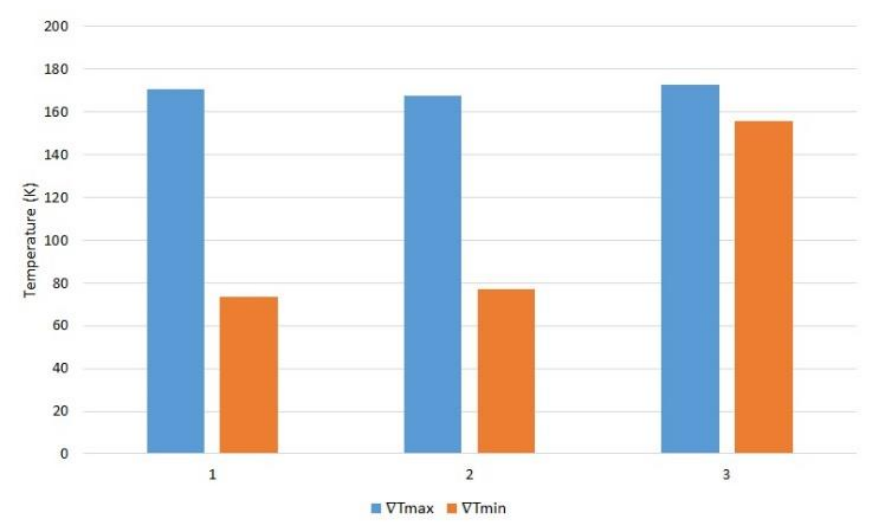

Fig. 14. Differences between maximum and minimum temperatures occurring on hot and cold parts of TEGs

In Figure 14, the temperature difference between the highest and lowest temperatures occurring on hot and cold parts of TEGs is shown. Power generation performance of TEGs enhances in line with the rate of such difference. When the graphic is examined, it is seen that only difference of the highest temperatures occurring on hot and cold surfaces is high in models no. 1 and 2. In model no. 3 , both the difference of the highest temperatures and difference of the lowest temperatures are high on hot and cold surfaces. According to such graphic, geometry no. 3 displays a highly ideal performance.

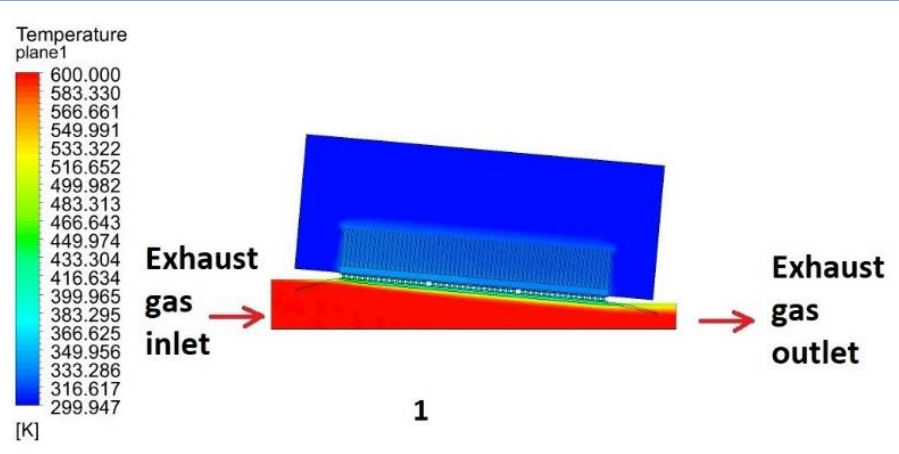

Fig. 15. Temperature distribution on the plane passing through the model no. 1
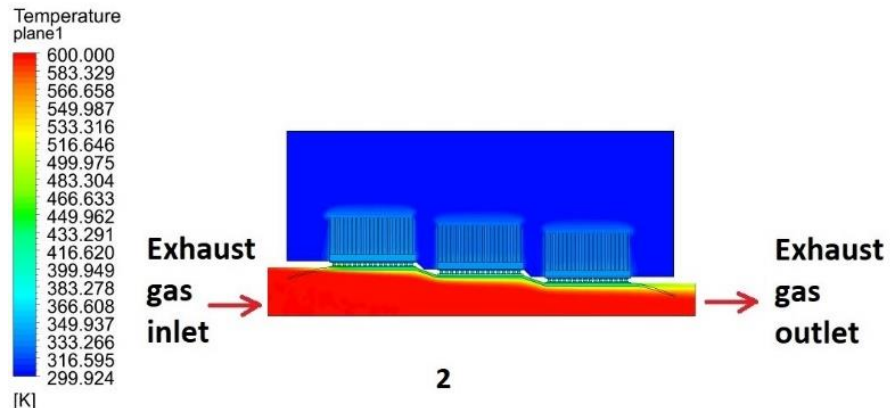

Fig. 16. Temperature distribution on the plane passing through the model no. 2
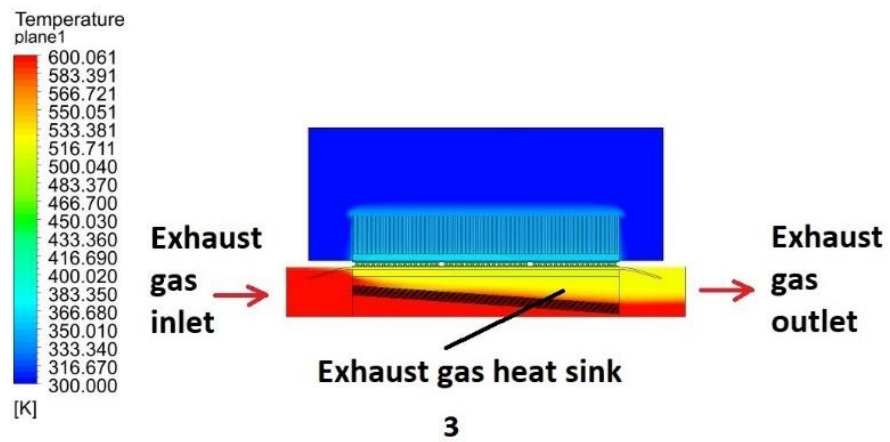

Fig. 17. Temperature distribution on the plane passing through the model no. 3

In Figures 15, 16 and 17, temperature distributions occurring on the planes passing horizontally through the models are shown. When such figures are examined, it is seen that the temperature of the exhaust gas decreases in parts closer to the walls of the heat exchanger due to the effect of cooling. In addition, the speed of gas decelerates here. The first two models have a shrinking structure. When temperature distributions of the third model are examined, it is observed that a proper temperature distribution occurs inside the exhaust gas. Such situation has resulted in a positive increase in hot surface temperatures of TEGs. Although the heat sink placed inside the exhaust gas has been designed not to prevent the gas flow as much as possible, it still prevents the gas flow. In order to mitigate such situation, the plane can be made larger or the heat sink can be smaller. 

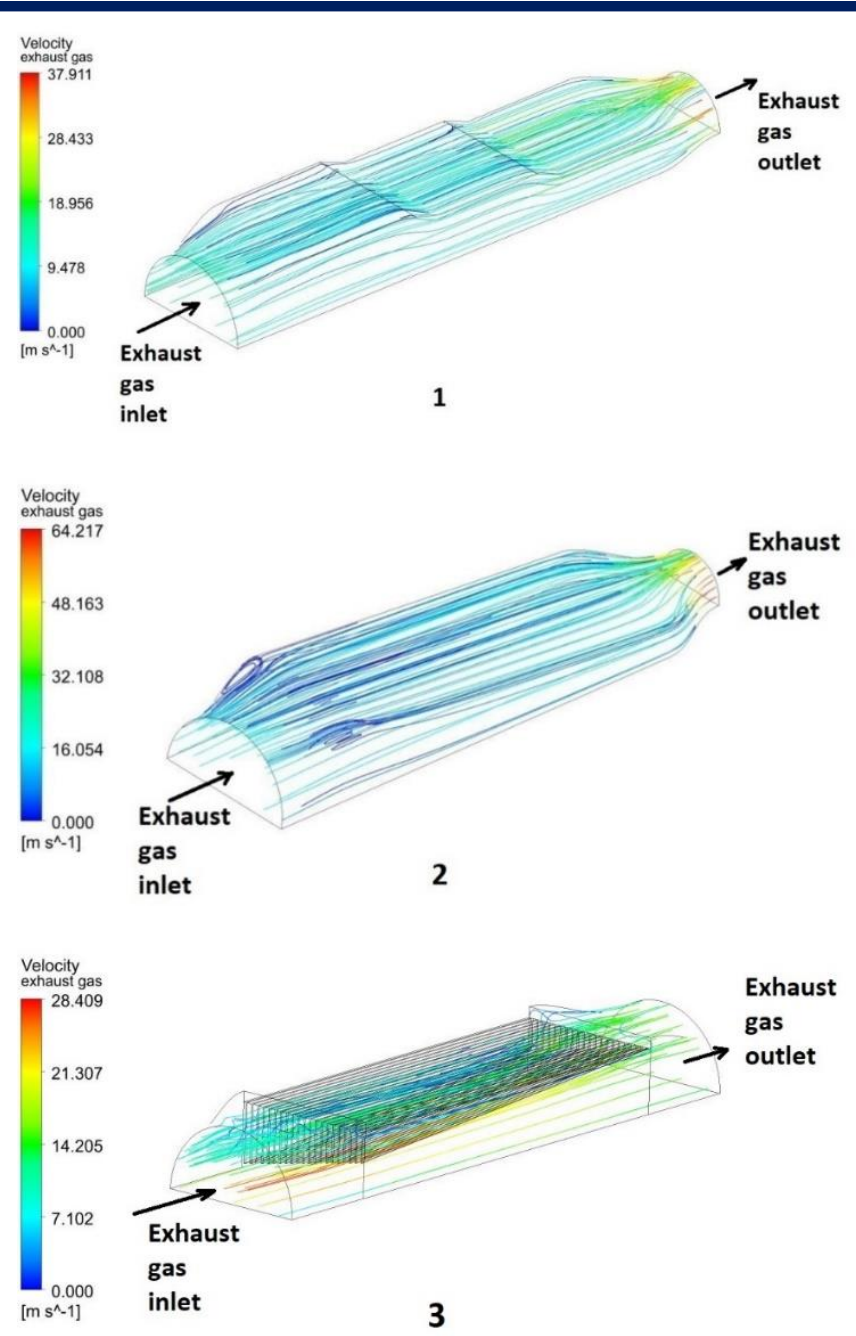

Fig. 18. Velocity flow lines of exhaust gas for each geometry

In Figure 18, velocity flow lines for the exhaust gas in designed models are shown. As there is a shrinking plane structure in models no. 1 and 2, the speed of gas increases at the outlet. Moreover, average gas speed has occurred high in such models as there is no hindrance for the flow. In model no. 3 , the heat sink placed inside the exhaust gas seems as a hindrance whether or not, and it reduces the average gas speed. Furthermore, a deceleration is observed as the flow is less at internal parts of the wings of heat sink and due to the effect of cooling.

\section{Conclusion}

Three models which are structurally different from each other have been examined in terms of temperature and exhaust has velocity/speed distributions. While deciding on such models, the situations that can constitute a problem in terms of production have been taken into consideration. It has been thought that the plane shrinking towards the outlet in models no. 1 and 2 can transfer the temperature better to the TEGs. However, in model no. 3, more heat energy has been transferred to TEGs thanks to the heat sink placed inside the exhaust gas. It has been observed that better heat distribution and more temperature distribution occur both on hot and cold surfaces of the TEGs in model no. 3. In addition, the temperature difference between hot and cold surfaces is higher in model no. 3. Such situation is regarded as a targeted result. When exhaust gas speeds are examined, it has been observed that the speed of exhaust gas in planes shrinking towards the outlet increased, and reached up to higher levels when compared to model no. 3. To conclude, all three models comprise difficulties in terms of production. Moreover, model no. 3 has given better results in terms of temperature distribution when compared to the others.

$\begin{array}{ll}\text { Nomenclature } \\ R e & : \text { Reynold number } \\ \rho & : \text { Density }\left(\mathrm{kg} \mathrm{m}^{-3}\right) \\ V & : \text { Velocity }\left(\mathrm{m} \mathrm{s}^{-1}\right) \\ D_{h} & : \text { Hydraulic diameter }(\mathrm{m}) \\ \mu & : \text { Dynamic viscosity }\left(\mathrm{kg} \mathrm{m}^{-1} \mathrm{~s}^{-1}\right) \\ T & : \text { Temperature }\left({ }^{\circ} \mathrm{C}\right) \\ f & : \text { Fanning Friction factor } \\ N u & : \text { Nusselt number } \\ P r & : \text { Prandtl number } \\ h_{e} & : \text { Heat convection coefficient }\left(\mathrm{W} \mathrm{m}^{-2} \mathrm{~K}^{-1}\right) \\ k_{e} & : \text { Thermal conductivity }\left(\mathrm{W} \mathrm{m}^{-1} \mathrm{~K}^{-1}\right) \\ c_{p} & : \text { Specific heat capacity }\left(\mathrm{J} \mathrm{kg}^{-1} \mathrm{~K}^{-1}\right)\end{array}$

\section{Conflict of Interest Statement}

The author declares that there is no conflict of interest

\section{References}

[1] Kim S, Park, S, Kim S, Rhi S. A Thermoelectric Generator Using Engine Coolant for Light-Duty Internal Combustion EnginePowered Vehicles. Journal of Electronic Materials. 2011;(40)5:812816.

[2] Kunt MA. An Experimental Investigation of Exhaust Waste Heat Recycling by Thermoelectric Generators Under Different Thermal Conditions for Internal Combustion Engines. Proc IMechE Part D: J Automobile Engineering. 2017;1-6.

[3] Kunt MA. İçten Yanmalı Motor Atık Isılarının Geri Kazanımında Termoelektrik Jeneratörlerin Kullanımı. El-Cezerî Fen ve Mühendislik Dergisi. 2016;(3)2:192-203.

[4] Kunt MA. A design of a liquid cooling thermoelectric generator system for the exhaust systems of internal combustion engines and experimental study on the effect of refrigerant fluid quantity on recovery performance. Pamukkale University Journal of Engineering Sciences 2019; 25: 7-12.

[5] Yang J, Stabler FR. Automotive Applications of Thermoelectric Materials. Journal of Electronic Materials. 2009;(38)7:1245-1251.

[6] Tang ZB, Deng YD, Su CQ, Shuai WW, Xie CJ. A Research on Thermoelectric Generator's Electrical Performance under Temperature Mismatch Conditions for Automotive Waste Heat Recovery. Case Studies in Thermal Engineering. 2015;5:143-150.

[7] Högblom O. Multiscale Simulation Methods for Thermoelectric Generators. Thesis for The Degree Of Doctor Of Philosophy. Chalmers University of Technology. Gothenburg, Sweden, 2016.

[8] Clark G. 6 Achieveing High Efficiency Thermoelectric Heating and Cooling with Metal Foam Heat Exchangers. Degree of Master of Applied Science Automotive Engineering. Universty of Ontario institue of Technology. April 2014.

[9] Deng YD, Fan W, Tang ZB, Chang XY, Ling K, Su CQ. Control Strategy for a 42-V Waste-Heat Thermoelectric Vehicle. Journal of Electronic Materials. 2013;(42)7:1522-1528. 
[10]Dhoopagunta S. Analytical Modeling and Numerical Simulation af a Thermoelectric Generator Including Contact Resistances. Degree of Master of Science in Engineering (Mechanical) Mechanical and Aerospace Engineering. Western Michigan University. December 2016.

[11]Attar A. Studying The Optimum Design of Automotive Thermoelectric Air Conditioning. Degree of Doctoral of Philosophy Mechanical and Aerospace Engineering. Western Michigan University. December 2015.

[12]Wang T, Ma S. Thermoelectric Generator Heat Performance Study About Improved Fin Structures. Thermal Science. 2018;(22)1:101112 .

[13]Massaguer A, Massaguer E, Comamala M, Cabot A, Ricart J, Deltell A. Experimental Analysis of an Automotive Thermoelectric Generator Under Different Engine Operating Regimes. Renewable Energy and Power Quality Journal. 2017;(1)15:619-623.

[14]Burnete NV, Mariasiu F, Moldovanu D, Depcik C. Simulink Model of a Thermoelectric Generator for Vehicle Waste Heat Recovery. Applied Sciences. 2021;(3)11:1-33.

[15]Gou X, Yang S, Xiao H, Ou Q. A dynamic model for thermoelectric generator applied in waste heat recovery. Energy. 2013;(52):201209.

[16]Liu X, Deng YD, Zhang K, Xu M, Xu Y, Su CQ. Experiments and Simulations on Heat Exchangers in Thermoelectric Generator for Automotive Application. Applied Thermal Engineering. 2014;(71):364-370.

[17]Incropera FP, DeWitt DP. Fundamentals of Heat and Mass Transfer. 4th ed. USA: John Wiley \& Sons, 2003, pp. 97-911.

[18]Bhatti MS, Shah RK. Turbulent and transition flow convective heat transfer in ducts. In Kakac S, Shah RK, Aung W, editors. Handbook of single-phase convective heat transfer. Wiley New York; 1987.

[19] Yu S, Du O, Diao H, Shu G,Jiao K. Start-Up Modes of Thermoelectric Generator Based on Vehicle Exhaust Waste Heat Recovery. Applied Energy. 2015;(138):276-290.

[20]Smith KD. An Investigation into the Viability of Heat Sources for Thermoelectric Power Generation Systems. A Thesis Submitted in Partial Fulfillment of the Requirements for the Degree of Master of Science in Mechanical Engineering. Rochester Institute of Technology. February 2009. 